\title{
PHYSICAL ACTIVITY LEVEL, FUNCTIONAL MOBILITY AND FALL RISK IN THE ELDERLY
}

\author{
Raesa Andrade da Silva', Glaudson Sá Brandão², Anderson Soares Silva³, Jessica Julioti Urbano³, \\ Ezequiel Fernandes de Oliveira ${ }^{3}$, Luis Vicente Franco Oliveira ${ }^{3}$, Aquiles Assunção Camelier ${ }^{4,5}$, Glauber Sá Brandão ${ }^{1,4}$.
}

\begin{abstract}
Introduction: Low levels of physical activity and functional mobility lead to greater difficulty in performing activities of daily living and are directly proportional to mortality in the elderly. Thus, there are the need to create mechanisms linked to the maintenance of the functional capacity, which assure the elderly autonomy and self-confidence. Objective: To verify the level of physical activity and functional mobility in the elderly and if this functional mobility suffers interference of the age group and physical activity. Methods: The study involved the elderly aged 60 and over, living in Senhor do Bonfim (BA), in the northeastern region of Brazil, from February to July 2015. The evaluation of the subjects occurred in a single session, with physical and general clinical evaluation, as well as the collection of sociodemographic, anthropometric and self-reported morbidities through the application of questionnaires. It was also carried out the Timed Up and Go test (TUG) to verify the levels of functional mobility and level of physical activity with application of the International Questionnaire of Physical Activity (IPAQ) adapted for the elderly. Results: In this study, 127 patients were studied, predominantly female (87\%) and mean age of $68 \pm 7$ years, and the majority of the elderly corresponded to the age group of 60 to 69 years. The elderly belonging to the group considered inactive (IPAQ up to $150 \mathrm{~min} /$ weekly) presented the execution time of TUG higher than the elderly in the group considered active (IPAQ $>150 \mathrm{~min} /$ weekly), with averaging time for carrying out the test of $10.5 \pm 2$ minutes and $8.9 \pm 2$ minutes respectively, with a statistically significant difference of $p<0.01$. And the execution time of TUG increased proportionally to the increase of the age group. Conclusion: Elderly with lower level of physical activity and belonging to the higher age groups present a higher risk of falls. Strategies should be developed to stimulate increased physical activity level and functional mobility of this population, especially among the older ones, reducing the incidence of falls and providing greater autonomy.
\end{abstract}

Keywords: motor activity, accidental falls, aged.

\section{INTRODUCTION}

Population aging has experienced a substantial acceleration in the last decades, being considered the most significant demographic change in the world, especially in developing countries. ${ }^{(1)}$ The natural and physiological aging process causes a progressive reduction of the functional capacity, causing greater difficulty in performing activities of daily living (ADL), making it more dependent. ${ }^{(2)}$ Thus, it is important to establish mechanisms which ensure the autonomy and self-confidence to elderly linked mainly to maintenance of functional capacity, as its decline increases vulnerability to the risk of falling due to a reduction in muscle strength, mobility and balance. ${ }^{(2,3)}$

The drop is defined as an involuntary transfer body to a level below the initial position, unable to be corrected in time and caused by multifactorial context, ${ }^{(4)}$ considered a public health and injury related to increased rates of mortality. ${ }^{(3,4)}$ Studies indicate that $30 \%$ to $60 \%$ of people aged 65 or over fall each year, and the elderly which have suffered a fall are at higher risk to fall in the following year..$^{(5)}$

Among the factors which predispose to falls in the elderly, the deterioration of functional mobility is among the most relevant and it is considered an important predictor in the assessment for falls risk. ${ }^{(6,7)}$ Functional mobility may be affected by intrinsic factors such as age and extrinsic factors such as physical activity level, both interfering negatively, with the increasing age predisposes to a reduction in functional mobility ${ }^{(8)}$ and the lower level of physical activity will decreased the functional mobility in the elderly. ${ }^{(10,11)}$

Corresponding Author: Glauber Sá Brandão. Rua Visconde do Rio Branco 162, Centro, Senhor do Bonfim, Ba, Brazil. Zip Code: 48970-000. E-mail: gbrandao@uneb.br. Phone: +55 74 98848-7858

${ }^{1}$ University of the State of Bahia (UNEB), DEDC-VII, Senhor do Bonfim (BA) Brazil.

${ }^{4}$ Postgraduate Program in Medicine and Human Health, Bahia School of Medicine and Public Health, Salvador (BA), Brazil.

Full list of author information is available at the end of the article.

Financial support: This study was funded by the State University of Bahia, through the Support Program for the Training of Teachers and Administrative Technicians (PAC), without influencing any of the stages of the study, from the conception, development, analysis and interpretation of the results. LVFO receive grants Research Productivity, modality PQ1B; Process no. 313053 / 2014-6 of National Council for Scientific and Technological Development (local acronym CNPq), Brazil.

Submission date 3 March 2017; Acceptance date 21 May 2017; Publication date 5 June 2017 
Thus, considering that low levels of physical activity and functional mobility are directly proportional to the mortality of the elderly, the present study aimed to verify the physical activity level and functional mobility of elderly and to evaluate if this functional mobility suffers interference of age and physical activity.

\section{METHODS}

\section{STUDY DESIGN}

It is a cross-sectional study with a quantitative approach on the physical activity level and functional mobility of the elderly in the community which present poor sleep quality. This study is part of a large project which aims to verify the effect of a home physical exercise program on the quality of sleep in elderlies. The research was approved by the Committee of Ethics in Research Involving Human Beings of the Bahian School of Medicine and Public Health - EBMSP, with CAAE: 39072514.6.0000.5544. All study participants signed the Informed Consent Form.

\section{PARTICIPANTS}

The study involved elderly, of both genders, aged 60 or older, living in the Senhor do Bonfim, Bahia, in northeastern Brazil, from February to July 2015. Recruitment for the study took place throughout the community, initially through the dissemination of study in local newspapers, radios, religious centers, elderly meeting groups, senior residency, ward associations and the Municipal Council, and in this announcement a telephone was provided for the interested people to contact the research team. Inclusion criteria were, both genders, age greater than or equal to 60 years and which had not performed exercises regularly for at least three months prior to the study. Participants with cognitive decline were excluded according to the Mental State Mini-Exam. ${ }^{(12)}$

The data was collected in one session, in which were held the physical evaluation and the general practice, collection of demographic data, anthropometric and morbidity self-reported by means of questionnaires, in addition to the evaluation of functional mobility with the achievement of the Timed Up and Go Test (TUG) ${ }^{(6)}$ and evaluation of physical activity level with application of the International Physical Activity Questionnaire (IPAQ) adapted for elderly. ${ }^{(13)}$

The collection of sociodemographic data and self-reported morbidities also occurred through the application of a questionnaire. For the verification of anthropometric variables such as body mass and height, a balance with stadiometer (mechanical anthropometric balance, $150 \mathrm{~kg}-$ Welmy $^{\circledR}$ ) was used; to measure the waist circumference, a tape measure was used and the body mass index (BMI) was calculated from the weight in kilograms divided by the height in meters squared.

The level of physical activity was assessed using the IPAQ adapted for elderly. ${ }^{(13)}$ This is a tool which allow to estimate the weekly energy expenditure of physical activities related to work, transportation, household chores and leisure, performed for at least 10 continuous minutes, with moderate and/or vigorous intensity, during a normal/usual week. This variable was dichotomized, and those who performed less than 150 minutes per week of moderate and/or vigorous physical activity were considered inactive and those who performed more than 150 minutes per week.

The functional mobility was evaluated by the TUG test, characterized as a basic test for evaluating the elderly mobility and considered as a measure with good sensitivity and specificity in predicting the risk of falls in the elderly. ${ }^{(7)}$ The used procedure was described in the original test, in which the participant starts at sitting position on a chair with armrests (seat height of $45 \mathrm{~cm}$ and arms of $65 \mathrm{~cm}$ ) firmly to the floor with the back resting on the back of the chair and guided to stand up, to walk a distance of three meters forward, to do a $180^{\circ}$ spin onto a mark made on the ground, get back and sit down again, executing as fast as possible, but safely and comfortable, minimizing the possibility of accidents. A stopwatch (Cassio Stopwatch, HS-70W-1) was used in which it was triggered from the verbal command "go" at the beginning of the test and stopped when the subject sat down again. All participants performed the test twice, and the time was recorded in the second performance.

According to the literature, TUG values less than 10 seconds suggest totally free and independent individuals with low risk of falls. The individuals who perform the TUG between 10 and 19 seconds are considered independent, however presenting some fragility and medium risk of falls and TUG of 20 and 29 seconds are in a denominated "gray zone", i.e., they demonstrate difficulties in the execution of tasks of daily living and limited functional mobility. Those with TUG 30 seconds or more, tend to be totally dependent for most basic and instrumental activities of daily living. ${ }^{(6,14)}$

\section{STATISTICAL ANALYSIS}

The data were tested for normality using the Kolmogorov-Smirnov test and submitted to a descriptive analysis through absolute frequencies and percentages for categorical variables and measures of central tendency and dispersion for numerical variables. Student's $t$ test was used to compare independent variables, assuming equal variances previously tested by Levene's test. For polytomic variables, were used one-way analysis of variance (one-way ANOVA) test followed by Tukey for multiple comparisons. For decision criteria, the significance level of $5 \%(p \leq 0.05)$ was adopted. The statistical procedures were processed and analyzed in Statistical Package of the Social Sciences ${ }^{\circledR}$ (SPSS) for Windows ${ }^{\circledR}$, version 21. 


\section{RESULTS}

One hundred and ninety-one potential participants were recruited from the community. Twenty-eight refused to participate in the examination, being enrolled 163 elderlies, of which 32 were excluded according to the eligibility criteria and 17 refused to perform the TUG, being selected 127 participants, representing $70 \%$ of the analyzed sample initially.

The Table 1 presents the number and percentage of sociodemographic data of the interviewed elderly. The predominance of females was $(87.4 \%)$, mean age $68 \pm 7$ years, the majority of subjects corresponding to the age group of 60 to 69 years. This is a population predominantly low income per capita $(84.3 \% \leq 2 \mathrm{SM})$, low education $(86.5 \%$ $\leq 3$ years of study) and, mostly living with relatives (68.5\%), married $(39.6 \%)$ or cohabiting (37\%).

Table 1. Socio-demographic characteristics of the subjects involved in the study.

\begin{tabular}{lcc}
\hline Socio-demographic characteristics & $(\mathbf{n}=\mathbf{1 2 7})$ & $\%$ \\
\hline Gender & 111 & 87.4 \\
Female & 16 & 12.6 \\
Male & & \\
Age (year) & 68 & 51.9 \\
60 to 69 & 48 & 36.6 \\
70 to 79 & 15 & 11.5 \\
$\geq 80$ & &
\end{tabular}

Education

$\begin{array}{lcc}\text { Illiterate } & 14 & 11.1 \\ 1 \text { to } 3 \text { years } & 95 & 75.4 \\ 4 \text { to } 7 \text { years } & 14 & 11.1 \\ 8 \text { years or more } & 3 & 2.4\end{array}$

Monthly income per capita (MW)

$\begin{array}{lcc}<1 \mathrm{MW} & 56 & 44.1 \\ 1 \text { to } 2 \mathrm{MW} & 51 & 40.2 \\ >2 \text { to } 3 \mathrm{MW} & 12 & 9.4 \\ >3 \mathrm{MW} & 8 & 6.3\end{array}$

Family composition

Live alone(a)

$40 \quad 31.5$

Live with relatives

87

68.5

Marital status

Single

10

Married

Widowed

Cohabiting

Divorced

50

7.9

39.6

5.5

37

10

$\mathrm{MW}$ (minimum wage), current during the study (in reais) $=\mathrm{R} \$ 788.00$
Regarding anthropometry, $47.2 \%$ of the elderly were overweight and $22.8 \%$ presented obesity, associated with the fact that $89.8 \%$ of the women had an abdominal circumference $\geq 80 \mathrm{~cm}$. Regarding the living habits, $90.1 \%$ of the elderly reported not smoking currently, and of these non-smokers, $12.2 \%$ were smoker in the past and, for the most, they did not report alcohol consumption (table 2).

Among the self-reported morbidities, anxiety (58.8\%), arthrosis (37.4\%), systemic arterial hypertension (33.6\%) and diabetes (26\%) were the most prevalent among the interviewed elderly. Regarding chronic pain, 38.9\% reported having some type of pain which remains chronic (table 3 ).

The Figure 1 shows the variations in TUG execution time, in relation to each of the three age groups in which the sample was divided, demonstrating that, increasing the age, there is

Table 2. Clinical and anthropometric data of the subjects involved in the study.

\begin{tabular}{lcc}
\hline \multicolumn{1}{c}{ Variables } & $(\mathrm{n}=\mathbf{1 2 7})$ & \% or mean \pm SD \\
\hline Weight & - & $64 \pm 11$ \\
BMI $\left(\mathrm{Kg} / \mathrm{m}^{2}\right)$ & 4 & 3.2 \\
$\quad$ Underweight $(<18.5)$ & 34 & 26.8 \\
$\quad$ Normal (18.5 to 24.9) & 60 & 47.2 \\
$\quad$ Overweight $(25.0$ to 29.9$)$ & 29 & 22.8 \\
$\quad$ Obesity $(\geq 30)$ & & \\
Abdominal Circumference $(\mathrm{cm})$ & & \\
$\quad$ Women & & \\
$\quad$ Increased risk $(\geq 80 \mathrm{~cm})$ & 99 & 89.2 \\
$\quad$ Men & & \\
*Increased risk $(\geq 94 \mathrm{~cm})$ & 2 & $137.8 \pm 18.3$ \\
Systolic blood pressure & - & $78.5 \pm 10$ \\
Diastolic blood pressure & - & \\
\hline
\end{tabular}

Data expressed as mean \pm SD (continuous variables) and frequencies (categorical variables); * Risk for cardiovascular disease

Table 3. Morbidities self-reported of the subjects involved in the study.

\begin{tabular}{lcc}
\hline \multicolumn{1}{c}{ Morbidities } & $(\mathbf{n}=\mathbf{1 2 7})$ & \% \\
\hline Diabetes & 34 & 26.0 \\
Systemic arterial hypertension & 44 & 33.6 \\
Urinary incontinence & 32 & 24.4 \\
Stroke & 6 & 4.6 \\
Respiratory disease & 14 & 10.7 \\
Arthritis & 24 & 18.3 \\
Arthrosis & 49 & 37.4 \\
Fibromyalgia & 6 & 4.6 \\
Depression & 29 & 22.1 \\
Anxiety & 77 & 58.8 \\
Chronic pain & 51 & 38.9 \\
\hline
\end{tabular}


also a statistically significant increase in TUG execution time. The analysis of variance identified that there was at least one statistically significant difference between the three means and in the multiple comparisons by Tukey's post-test method, there was a significant difference between all means, $p<0.001$.

The mean time of TUG, in seconds, for each age groups was $8.3 \pm 1.6$ for the elderly from 60 to 69 years; $9.6 \pm 2$ for 70 to 79 years and $11 \pm 2$ for 80 years or more and the TUG mean of the whole sample was $9 \pm 2$.

Subjects belonging to the group considered inactive (IPAQ to $150 \mathrm{~min} /$ week) presented an execution time of TUG greater than the elderly group considered active (IPAQ > $150 \mathrm{~min} /$ week), with mean time for completion of the test of $10.5 \pm 2$ and $8.9 \pm 2$ respectively, with a statistically significant difference with $p<0.01$ (Figure 2).

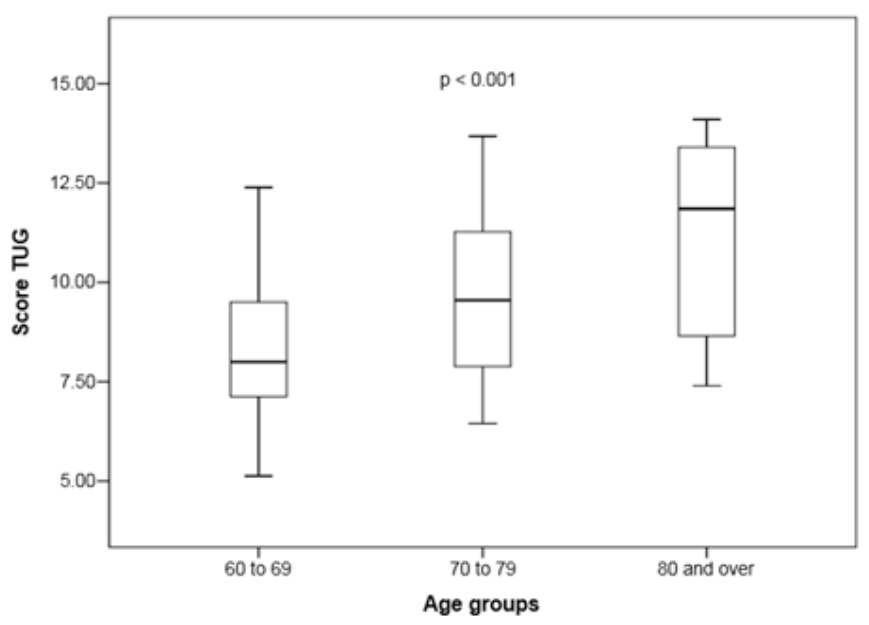

Figure 1. TUG score, in seconds, for each of the three age groups of subjects in the study.

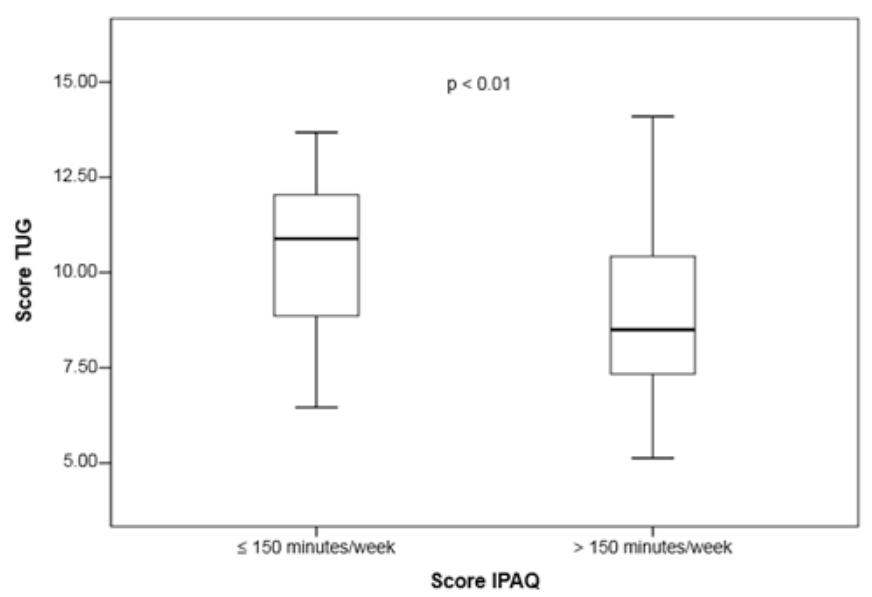

Figure 2. TUG score, in seconds, regarding physical activity level according to the IPAQ of the subjects involved in the study.

\section{DISCUSSION}

The greater longevity of women is demonstrated by the predominance of female elderly in the present study (87.4\%). This feminization of old age occurred always in history and in various parts of the world. ${ }^{(15)}$ The mean age of the sample involved in this study was $68 \pm 7$ years, with a prevalence of 60 to 69 years (51.9\%), as also observed in other studies..$^{(16-18)}$ Most of the subjects in our research reported only up to three years of school education (86.5\%), which sets the difficulty of school access, historically presented by Brazilian low-income population, especially regarding the women. ${ }^{(19)}$ This low level of education, reduces the ability of understanding and acceptance of health education programs. ${ }^{(20)}$

The interviewees mostly showed $(44.1 \%)$ per capita income less than one minimum wage. This precarious income predisposes to situations of great social vulnerability, making the elderly susceptible to aggravation of pre-existing diseases and to the appearance of new conditions of health decline. ${ }^{(21)}$ Associated with this economic status, $68.5 \%$ of the sample lives with relatives, most married (39.4\%) or cohabiting (37\%), a situation which converges with other population-based studies $^{(22,23)}$ and it is considered positive by most of the elderly by enabling the support of the family in carrying out daily activities. ${ }^{(24)}$

Anthropometry identified that $70 \%$ of elderly are overweight ${ }^{(25)}$ and $89.8 \%$ of women have abdominal circumference $>80 \mathrm{~cm}$, being an indicative of increased risk for cardiovascular disease, as shown in other studies. ${ }^{(26,27)}$ Associated with this health condition and confirming other studies of aging, it was observed a high prevalence of chronic diseases such as anxiety, chronic pain, osteoarthritis, hypertension and diabetes mellitus. ${ }^{(23,28)}$

The natural aging process causes structural and functional deterioration, generating alterations in the psychomotor function and balance, predisposing to falls. ${ }^{(29)}$ The risk of falls in the elderly may be evaluated by performing the TUG test, and an adequate test performance may be indicative of good functional recovery and be used as a predictor for the risk of falls. ${ }^{(2,3,7)}$ The present study demonstrates that subjects belonging to the older age groups, require more time to complete the TUG, thus, and according to the considerations Podsiadlo and Richardson, ${ }^{(6)}$ we may interpret that the increase in age causes a decline in functional mobility and consequently increases the risk of falls in the elderly, corroborating other studies that demonstrated the positive association of increasing age with a greater propensity for falls. ${ }^{(8,9)}$ Shumway-Cook et. al., verified the ability of the elderly to perform the TUG under specific conditions, and additional tasks (cognitive or physical) were performed simultaneously to the execution of the test. The authors verified that the TUG is able to predict the risk of falls in the elderly and that the capacity of execution decreases with advancing age. ${ }^{(7)}$ 
Generally, the elderly present a progressive reduction in muscle performance, aerobic endurance and postural balance, influencing on their functional capacity and independence, resulting in a reduction in the level of physical activity. ${ }^{(29)}$ In this study, the subjects considered inactive, required more time to complete the TUG compared to active, indicating that the level of physical activity interferes significantly in functional mobility of elderly, confirming other studies which evaluated community elderlies with functional limitations and found that those who were more actives, performed better on tests of physical capacity and mobility than the less active elderlies. ${ }^{(10)}$ In a recent systematic review, it was shown that high levels of physical activity are also associated with greater functional capacity in the elderly. ${ }^{(11)}$

\section{CONCLUSION}

The results of the present study suggest that the physical activity level and the age group interfere in the functional mobility of the elderly, and it may be interpreted that elderly with lower physical activity level and belonging to the higher age groups, present a higher risk of falls. Therefore, strategies should be developed to stimulate the increase of the physical activity level and functional mobility in this population, especially among the older ones, reducing the incidence of falls and providing greater autonomy.

\section{AUTHOR'S CONTRIBUTIONS}

RAS, AAC, LVFO and GSB defined the concept of the study, created the hypothesis, and wrote the original proposal. RAS, AAC, LVFO, ASS, JJU and GSB contributed significantly to writing this proposal. RAS, GSB, RAOP, JJU, ASS, LVFO, $A A C$ and GSB were involved in the critical review of the manuscript. RAS, AAC, LVFO, EFO, JJU, ASS and GSB wrote this protocol role, with the contribution of all co-authors. All authors read and approved the final manuscript.

\section{CONFLICTS OF INTEREST}

The authors declare that they have no conflicts of interest.

\section{AUTHOR DETAILS}

²Diagnostic and Specialty Clinics (IMAIS), Senhor do Bonfim (BA), Brazil. ${ }^{3}$ Sleep Laboratory, Rehabilitation Sciences Master's and PhD Degree Program, Nove de Julho University (UNINOVE), Sao Paulo, (SP), Brazil.

${ }^{5}$ University of the State of Bahia (UNEB), DCV, Salvador (BA) Brazil.

\section{REFERENCES}

1. IBGE. Instituto Brasileiro de Geografia e Estatística - IBGE. Dados do Censo 2010. Diário Oficial da República Federativa do Brasil, Brasília, DF. 2010.

2. Valduga R, Lopes BS, Farias DL, Nascimento DC, Valduga LV, Prestes J, et al. Risco de quedas e sua relação com a funcionalidade e medo de cair em idosas. Rev Bras Ciência e Mov. 2016;24(1):153-66.

3. Santos RKM, Maciel ÁCC, Britto HMJS, Lima JCC, Souza TO. Prevalência e fatores associados ao risco de quedas em idosos adscritos a uma Unidade Básica de Saúde do município de Natal, RN, Brasil. Cien Saude Colet. 2015;20(12):3753-62.

4. Sociedade Brasileira de Geriatria e Gerontologia. Quedas em Idosos: Prevenção. Assoc Médica Bras e Cons Fed Med Quedas. 2008;1-10.
5. Reyes-Ortiz CA, Al Snih S, Markides KS. Falls among elderly persons in Latin America and the Caribbean and among elderly Mexican-Americans. Pan Am J public Heal. 2005;17(5-6):362-9.

6. Podsiadlo D, Richardson S. The Timed "Up \&amp; Go": A Test of Basic Functional Mobility for Frail Elderly Persons. J Am Geriatr Soc. 1991;39(2):142-8.

7. Shumway-Cook A, Brauer S, Woollacott M. Research Report Predicting the Probability for Falls in Community-Dwelling Older Adults Using the Timed Up \& Go Test. J Am Phys Ther Assoc. 2000;80:896-903.

8. Souza C, Valmorbida L, Oliveira J, Bosatto A, Lorenzini M, Knorst $M$, et al. Mobilidade funcional em idosos institucionalizados e não institucionalizados. Rev Bras Geriatr e Gerontol. 2013;16(2):285-93.

9. Almeida ST, Soldera CLC, Carli GA, Gomes I, Resende TL. Análise de fatores extrínsecos e intrínsecos que predispõem a quedas em idosos. Rev Assoc Med Bras. 2012;58(4):427-33.

10. Morie M, Reid KF, Miciek R, Lajevardi N, Choong K, Krasnoff JB, et al. Habitual Physical Activity Levels are Associated with Performance in Measures of Physical Function and Mobility in Older Men. J Am Geriatr Soc. 2011;58(9):1727-33.

11. Paterson D, Warburton D. Physical activity and functional limitations in older adults: a systematic review related to Canada's Physical Activity Guidelines. Int J Behav Nutr Phys Act. 2010;7(1):38.

12. Brucki SMD, Nitrin R, Caramelli P, Bertolucci PHF, Okamoto IH. Sugestões para o uso do mini-exame do estado mental no Brasil. Arq Neuropsiquiatr. 2003;61(3 B):777-81.

13. Mazo GZ, Benedetti TB. Adaptation of the international physical activity questionarie for the elderly. Rev Bras Cineantropometria e Desempenho Hum. 2010;12(6):480-4.

14. Siggeirsdóttir K, Jónsson BY, Jónsson H Jr, Iwarsson S. The timed “Up \& Go" is dependent on chair type. Clin Rehabil. 2002;16(6):609-16.

15. Austad SN, Bartke A. Sex Differences in Longevity and in Responses to Anti-Aging Interventions: A Mini-Review. Gerontology. 2015;62(1):40-6.

16. Fernandez-Martinez B, Prieto-Flores ME, Forjaz MJ, Fernández-Mayoralas G, Rojo-Pérez F, Martínez-Martín P. Self-perceived health status in older adults : regional and sociodemographic inequalities in Spain Estado de saúde percebido em idosos: desigualdades regionais e sociodemográficas na Espanha. Rev Saúde Pública. 2012;46(2):310-9.

17. Regina M, Alvarenga M, Accioly M, Domingues $R$, Amendola F, Faccenda O. Rede de suporte social do idoso atendido por equipes de Saúde da Família Social support networks for elderly patients attended by Family Health teams. Cien Saude Colet. 2011;16(5):2603-11.

18. Roberto J, Fhon S, Diniz MA, Leonardo KC, Haas VJ, Aparecida R, et al. Síndrome de fragilidade relacionada à incapacidade funcional no idoso * (MIF) e Escala de Lawton e Brody. A MIF foi validada. Acta Paul Enferm. 2012;0(0):3-8.

19. Paskulin LMG, Vianna LAC. Perfil sociodemográfico e condições de saúde auto- referidas de idosos de Porto Alegre Sociodemographic profi le and self- referred health conditions of the elderly in a city of Southern Brazil ABSTRACT. Rev Saúde Pública. 2007;41(5):757-68.

20. Junior RT, Machado MS, Carvalho F. Perfil demográfico e condições sanitárias dos idosos em área urbana do Sudeste do Brasil. Rev Saúde Pública. 1996;30(5):485-98.

21. Louvison MCP, Lebrão ML, Duarte YAO, Laurenti R. Desigualdades nas condições de saúde e no uso de serviços entre as pessoas idosas do município de São Paulo: uma análise de gênero e renda. Saúde Coletiva. 2008;5(24):189-94.

22. Silva IT, Junior EPP, Vilela ABA. Autopercepção de saúde de idosos que vivem em estado de corresidência. Rev Bras Geriatr e Gerontol. 2010;17(2):275-87.

23. Wilker J, Clares B, Galiza FT, Queiroz TA, Centers H, Data D, et al. Perfil de idosos cadastrados numa unidade básica de saúde da família de FortalezaCE. Rev RENE. 2011;12:988-94. 
24. Silva HO, Carvalho MJAD, Lima FEL, Rodrigues LV. Perfil epidemiológico de idosos frequentadores de grupos de convivência no município de Iguatu, Ceará. Rev Bras Geriatr e Gerontol. 2011;14(1):123-33.

25. Associação Brasileira para o Estudo da Obesidade e da Síndrome Metabólica Diretrizes brasileiras de obesidade 2009/2010 / ABESO. 3.ed., Itapevi, SP: AC Farmacêutica, 2009, p. 11-83.

26. Cercato C, Mancini MC, Maria A, Arguello C, Passos Q, Mara S, et al. Systemic hypertension, diabetes mellitus, and dyslipidemia in relation to body mass index: evaluation of a brazilian population. Rev Hosp Clin Fac Med S Paulo. 2004;59(3):113-8.
27. Peeters A, Barendregt JJ, Willekens F, Mackenbach JPA, Mamun ABL. Obesity in adulthood and its consequences for life expectancy: a life-table analysis. Ann Interm Med. 2003;138(1):24-32.

28. Cristina I, Freitas M. O perfil do idoso de baixa renda no Município de São Carlos, São Paulo, Brasil : um estudo epidemiológico. Cad Saúde Pública. 2004;20(6):1575-85.

29. Ensrud KE, Ewing SK, Cawthon PM, Fink HA, Taylor BC, Cauley JA, et al. A Comparison of Frailty Indexes for the Prediction of Falls, Disability, Fractures and Mortality in Older Men. J Am Geriatr Soc. 2010;57(3):492-8. 